\title{
Stroma-supported Culture of Childhood B-Lineage Acute Lymphoblastic Leukemia Cells Predicts Treatment Outcome
}

\author{
Masa-aki Kumagai, ${ }^{\star}$ Atsushi Manabe, ${ }^{\star}$ Ching-Hon Pui, ${ }^{\star \neq||}$ Frederick G. Behm, ${ }^{\ddagger \mid}$ Susana C. Raimondi, ${ }^{\sharp \mid}$ Michael L. Hancock, ${ }^{\S}$ \\ Hazem Mahmoud, ${ }^{*}$ William M. Crist, ${ }^{* \|}$ and Dario Campana*\| \\ Departments of *Hematology-Oncology, ${ }^{\ddagger}$ Pathology and Laboratory Medicine, and ${ }^{\S}$ Biostatistics, St. Jude Children’s Research Hospital, \\ Memphis, Tennessee 38101; and ${ }^{\|}$University of Tennessee College of Medicine, Memphis, Tennessee 38101
}

\begin{abstract}
We developed a stroma cell culture system that suppresses apoptosis of malignant cells from cases of B-lineage acute lymphoblastic leukemia. By multiparameter flow cytometric measurements of cell recovery after culture on stromal layers, we assessed the growth potential of 70 cases of newly diagnosed B-lineage acute lymphoblastic leukemia and related the findings to treatment outcome in a single program of chemotherapy. The numbers of leukemic cells recovered after $7 \mathrm{~d}$ of culture ranged from $<1$ to $292 \%$ (median, 91\%). The basis of poor cell recoveries from stromal layers appeared to be a propensity of the lymphoblasts to undergo apoptosis. The probability of event-free survival at $4 \mathrm{yr}$ of follow-up was $50 \pm 9 \%$ (SE) among patients with higher cell recoveries $(>91 \%)$, and $94 \pm 6 \%$ among those with reduced cell recoveries $(\leq 91 \% ; P=0.0003)$. The prognostic value of leukemic cell recovery after culture exceeded estimates for all other recognized high-risk features and remained the most significant after adjustment with all competing covariates. Thus, the survival ability of leukemic cells on bone marrow-derived stromal layers reflects aggressiveness of the disease and is a powerful, independent predictor of treatment outcome in children with B-lineage acute lymphoblastic leukemia. (J. Clin. Invest. 1996. 97:755-760.) Key words: cell death • cell division - cultured tumor cells • flow cytometry $\bullet$ prognosis
\end{abstract}

\section{Introduction}

Childhood B-lineage acute lymphoblastic leukemia (ALL), the most common form of cancer in children, arises in the bone marrow from malignantly transformed B-lymphoid progenitors. In general, B-lineage ALL is highly responsive to intensive multiagent chemotherapy, with more than $70 \%$ of patients becoming long-term survivors in recent studies (1-4). To im-

Address correspondence to Dario Campana, Department of Hematology-Oncology, St. Jude Children's Research Hospital, 332 North Lauderdale, Memphis TN 38101. Phone: 901-495-2528; FAX: 901526-7151.

Received for publication 8 September 1995 and accepted in revised form 15 November 1995.

1. Abbreviations used in this paper: ALL, acute lymphoblastic leukemia; CI, confidence interval; CNS, central nervous system; LDH: lactate dehydrogenase.

J. Clin. Invest.

(C) The American Society for Clinical Investigation, Inc.

0021-9738/96/02/0755/06 \$2.00

Volume 97, Number 3, February 1996, 755-760 prove cure rates further, it will be necessary to develop more sensitive methods of identifying high-risk patients early in the clinical course, permitting appropriate intensification of therapy. Conversely, it may be possible to recognize small subgroups with otherwise unfavorable prognostic features who could be cured with standard or reduced treatment.

The ability of the leukemic clone to grow is likely to influence the degree of tissue infiltration, the likelihood of developing multidrug resistance, and, ultimately, treatment outcome. Until recently, however, leukemic growth potential has been difficult to assess because cells from the majority of cases rapidly die by apoptosis when placed in vitro (5). We found that apoptosis of leukemic lymphoblasts is prevented by direct contact with bone marrow-derived stromal layers, and established a culture system for maintaining B-lineage leukemic cells on stromal layers in a serum-free environment (5-9). The fraction of originally seeded cells remaining in culture varied widely, suggesting that the cell recovery rate might be used as an assay to evaluate the growth potential of the leukemic clone in individual patients and assess its relation with treatment outcome. This hypothesis was tested in 70 well-characterized cases of childhood B-lineage ALL treated in a single program of intensive chemotherapy. As reported here, measurements of leukemic cell recovery after culture on stromal layers identify two distinct, prognostically relevant forms of ALL that are difficult to distinguish by conventional means.

\section{Methods}

Characterization of leukemic cells and treatment plan. This study included all bone marrow samples obtained from children with B-lineage ALL enrolled in the Total Therapy Study XII at this institution from September 1988 to November 1991 with sufficient cells for culture. Thus, a total of 70 patients out of the 147 enrolled in Study XII were represented in the analysis. Their presenting features, summarized in Table I, were typical of those of larger cohorts with this immunologic subtype of ALL (3), and were not significantly different from those of the remaining 77 patients (not shown), with the exception of a higher proportion of cases with leukocyte counts $>50$ $\times 10^{9} /$ liter ( 17 of 70 vs. 7 of $77 ; P=0.015$ by Fisher's exact test).

Immunophenotyping, performed by standard techniques, yielded an unequivocal diagnosis of B-lineage ALL in each case $(>80 \%$ of the blast cells were $\mathrm{CD} 19^{+}, \mathrm{CD} 22^{+}$, and lacked surface Ig). Chromosomes were analyzed by conventional banding methods. For flow cytometric analysis of DNA content, the cells were processed as described earlier (6). Scanning electron microscopy and gel electrophoresis in the DNA fragmentation studies were performed as described in References 5 and 6. Staining of leukemic cells for EBV nuclear antigen (EBNA-2) was performed with a specific mAb (gift of Dr. M. Rowe, Birmingham, U.K.; reference 10); the Raji cell line was used as a positive control.

The treatment plan followed the Total Therapy Study XII protocol (11). Briefly, remission induction chemotherapy consisted of prednisone, vincristine, daunorubicin, and L-asparaginase followed 


\begin{tabular}{|c|c|c|c|c|}
\hline \multirow[b]{2}{*}{ Feature } & \multirow[b]{2}{*}{ Category } & \multicolumn{2}{|c|}{ Percent cell recovery* } & \multirow[b]{2}{*}{$P$-value } \\
\hline & & $\leq 91$ & $>91$ & \\
\hline \multirow[t]{3}{*}{ Ploidy ${ }^{\S}$} & 51-65 chromosomes & 17 & 1 & \multirow[t]{3}{*}{$<0.001$} \\
\hline & $<46$ chromosomes & 0 & 4 & \\
\hline & others & 17 & 30 & \\
\hline \multirow[t]{2}{*}{ Leukocyte count $\left(\times 10^{9} /\right.$ liter $)$} & $\leq 50$ & 32 & 21 & \multirow[t]{2}{*}{0.004} \\
\hline & $>50$ & 3 & 14 & \\
\hline \multirow[t]{2}{*}{ Serum LDH (U/liter) } & $\leq 770$ & 32 & 24 & \multirow[t]{2}{*}{0.034} \\
\hline & $>770$ & 3 & 11 & \\
\hline \multirow[t]{3}{*}{ Age (yr) } & $<1$ & 0 & 4 & \multirow[t]{3}{*}{0.141} \\
\hline & $1-10$ & 29 & 24 & \\
\hline & $>10$ & 6 & 7 & \\
\hline \multirow[t]{2}{*}{ Percentage S phase cells ${ }^{\S}$} & $\leq 6.4$ & 13 & 18 & \multirow[t]{2}{*}{0.145} \\
\hline & $>6.4$ & 22 & 14 & \\
\hline \multirow[t]{2}{*}{ CNS involvement ${ }^{\S}$} & No & 27 & 26 & \multirow[t]{2}{*}{0.346} \\
\hline & Yes & 4 & 8 & \\
\hline \multirow[t]{2}{*}{ Phenotype } & Early pre-B & 23 & 22 & \multirow[t]{2}{*}{0.99} \\
\hline & Pre-B\| & 12 & 13 & \\
\hline \multirow[t]{2}{*}{ Sex } & Female & 19 & 19 & \multirow[t]{2}{*}{0.99} \\
\hline & Male & 16 & 16 & \\
\hline
\end{tabular}

*The median percentage of $\mathrm{CD} 19^{+}$lymphoblasts recovered after $7 \mathrm{~d}$ of culture on stromal layers relative to the number recovered after $1 \mathrm{~h}$ was $91 \%$ (range $=<1-292 \%) ;{ }^{*}$ by Fisher's exact test; ${ }^{\S}$ data not available for all cases; ${ }^{\prime}$ cases with cytoplasmic $\mu$ heavy-chain expression.

by teniposide plus cytarabine. Children who entered complete remission received $120 \mathrm{wk}$ of continuation therapy with daily mercaptopurine and weekly methotrexate, interrupted every 6 wk during the first year with alternating pulses of high-dose methotrexate or teniposide plus cytarabine pulse therapy (five courses each). All patients received age-adjusted doses of triple intrathecal methotrexate, hydrocortisone, and cytarabine during the first year of continuation therapy. Cranial irradiation and five doses of intrathecal chemotherapy were then given to patients with higher-risk ALL (18 Gy) or those with central nervous system (CNS) leukemia at diagnosis (24 Gy).

Preparation of bone marrow cells and culture experiments. Bone marrow stromal cells were prepared by culturing $\mathrm{T}$ cell-depleted mononuclear cells from healthy bone marrow donors in 96-well flatbottomed microtiter plates (Costar Corp., Cambridge, MA) with RPMI 1640 (Whittaker Bioproducts Inc., Walkersville, MD), 10\% FCS (Whittaker Bioproducts Inc.) and $10^{-6} \mathrm{M}$ hydrocortisone (Sigma Chemical Co., St. Louis, MO), as previously described (5-9). All leukemic samples were placed in culture $(n=7)$ or cryopreserved $(n=63)$ within 5 h of collection; cell viability exceeded $80 \%$ by staining with trypan-blue dye. In preliminary experiments with nine B-lineage ALL cases, in which both fresh and cryopreserved samples were cultured on stromal layers, cryopreservation did not significantly affect lymphoblasts' survival and growth in culture (not shown). Leukemic lymphoblasts, depleted of T cells with CD4- and CD8-conjugated immunomagnetic beads (Dynal, Oslo, Norway) were resuspended at a final concentration of $1.5 \times 10^{6} / \mathrm{ml}$ in AIM-V (GIBCO BRL, Grand Island, NY), a chemically defined, serum-free medium that contains insulin as its sole growth factor. $200 \mu \mathrm{l}$ of the suspension were then seeded onto marrow stromal cells that had been extensively washed to remove FCS and hydrocortisone or were placed in identical plates without stroma. Cells were cultured for $7 \mathrm{~d}$ in an incubator set at $37^{\circ} \mathrm{C}, 5 \% \mathrm{CO}_{2}$ and $90 \%$ humidity.

At the termination of cultures, cells were harvested by vigorous pipetting, incubated with $\mathrm{CD} 19 \mathrm{mAb}$ conjugated to FITC, and CD3 conjugated to phycoerythrin (both from Becton Dickinson Co., San Josè, CA), and analyzed with a FACScan ${ }^{\circledR}$ flow cytometer with Lysis II software (Becton Dickinson Co.) as previously described (5-9). After $7 \mathrm{~d}$ of culture the percentage of cell recovery was calculated as fol- lows: (no. of CD19+ lymphoblasts after $7 \mathrm{~d}$ of culture) $\times 100 /($ no. of $\mathrm{CD} 19^{+}$lymphoblasts after $1 \mathrm{~h}$ of culture). All results are reported as the mean of at least duplicate experiments (SEM, 0.1-8.9\%). Leukemic cells were counted without knowledge of the patient's clinicobiologic features or treatment response.

To ensure that the source of stromal layers was not a factor in the survival and proliferation of leukemic lymphoblasts in vitro, we compared the growth-supporting capabilities of stromal layers prepared from different donors. In tests with 28 ALL samples, these preparations yielded essentially the same results $(r=0.953, P<0.001$ by Spearman's linear regression analysis).

Statistical analysis. Distributions of commonly measured presenting features, according to the percentage of viable leukemic cells (above or below the median percent value) recovered after $7 \mathrm{~d}$ of culture, were compared by Fisher's exact test. The probability of surviving without an adverse event (i.e., failure to enter remission, relapse, or death due to any cause) was estimated by the method of Kaplan and Meier; associated standard errors were calculated by the method of Peto et al. (12). The prognostic importance of the percentage of leukemic cells recovered after culture was determined, first, by univariate analysis with leukocyte count, age at diagnosis, and other factors known to influence outcome in ALL, and then by stratified analysis with covariates attaining significance in the univariate model. All comparisons of event-free survival distributions were made by the exact logrank test, using the StatXact-Turbo statistical software for exact nonparametric inference (Cytel Software Corp., Cambridge, MA). The odds ratio and $95 \%$ confidence interval (CI) for a patient with the adverse category of a given prognostic factor was computed according to Peto and coworkers (13). A $P$ value of $<0.05$ was taken to indicate statistical significance.

\section{Results}

Survival of leukemic lymphoblasts on stromal layers. To measure the growth potential of leukemic lymphoblasts, B-lineage ALL cells from diagnostic bone marrow samples were cultured on allogeneic bone marrow-derived stromal layers in se- 


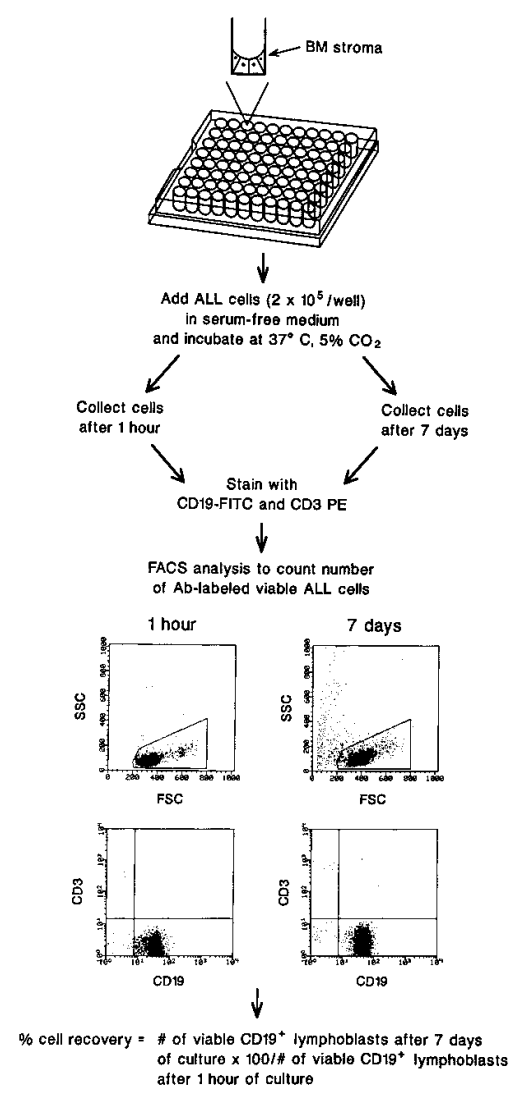

Figure 1. Outline of the tissue culture technique and cell counting protocol used in this study. $B M$, bone marrow; $A b$, antibody. $P E$, phycoerythrin.

rum-free medium for $7 \mathrm{~d}$. At the termination of the cultures, the numbers of viable lymphoblasts expressing the B cell marker CD19 were counted by flow cytometry (5-9) and compared to those recovered after $1 \mathrm{~h}$ of culture (Fig. 1). The numbers of $\mathrm{CD} 19^{+}$cells recovered after $7 \mathrm{~d}$ of culture ranged from
$<1$ to $292 \%$ (median, $91 \%$ ) of those originally seeded. Among the samples with $>91 \%$ cell recovery, 34 were cryopreserved and 1 was cultured fresh; cases with $\leq 91 \%$ cell recovery included 29 cryopreserved and 6 fresh samples $(P=0.106)$.

To confirm that this assay reflected the loss or gain of leukemic lymphoblasts, we compared immunophenotypes before and after culture. In four samples tested after 8, 56, 59, and $84 \mathrm{~d}$ of culture, the fractions of cells expressing CD19, CD3, surface Ig, CD10, CD13, CD15, CD33, CD65, and CD34 were essentially unchanged from earlier findings (not shown). None of the three samples examined (collected after 8, 59, and $84 \mathrm{~d}$ of culture) reacted with an $\mathrm{mAb}$ specific for the EBNA-2 protein (10), excluding the possibility that EBV-stimulated lymphoblastoid lines had overgrown leukemic cells.

Mechanism of leukemic cell death. During efforts to identify the basis of poor cell recovery (i.e., $<50 \%$ ) from stromal layer cultures, we observed shifts in cellular light-scattering properties that were reminiscent of those associated with apoptosis, e.g., after treatment with corticosteroids or antiApo 1/Fas antibodies (Fig. 2 A; 7,14). These changes consisted of a reduction in forward scatter, indicating a reduction in cell size, and an increase in side scatter, indicating an increase in cell granularity. By light microscopy, the lymphoblasts from these cases showed prominent nuclear fragmentation after 72 $96 \mathrm{~h}$ of culture, which is typical of apoptosis (not shown). Additional evidence that cells died from apoptosis was obtained by flow cytometry, which showed reduced DNA staining due to the release of fragments from apoptotic cells (Fig. $2 B ; 15$ ), and by gel electrophoresis, which showed a typical ladder of multiples of 180 basepair fragments (Fig. $2 C$; 16). Finally, apoptotic cell death was also suggested by scanning electron microscopy. After $5 \mathrm{~d}$, many cells had begun to deteriorate, and the overall cellularity of the cultures was visibly decreased as compared to control cultures, in which $>91 \%$ of cells were recovered after $7 \mathrm{~d}$ (Fig. $2 \mathrm{D}$ ).

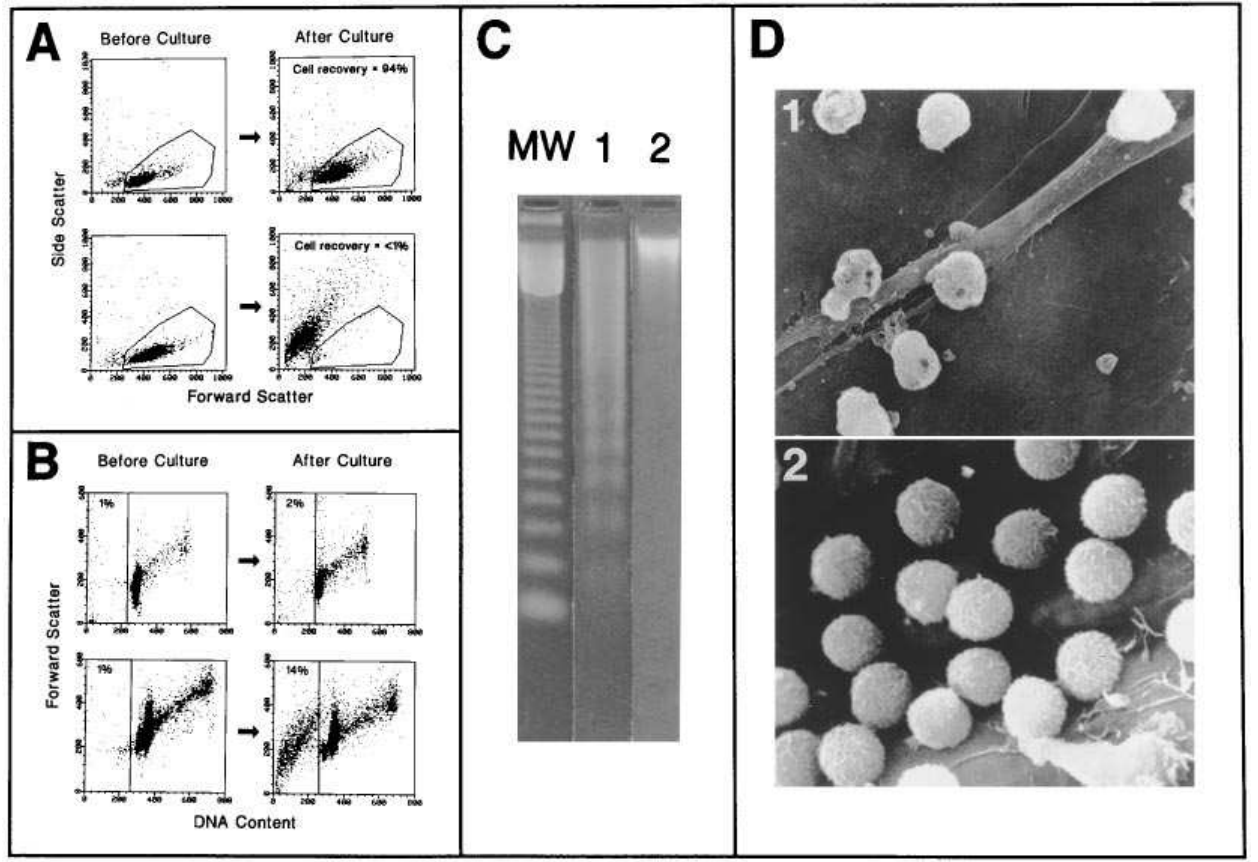

Figure 2. Apoptotic death, the basis of poor cell recovery from stromal layers. In all cases with particularly low cell recovery (i.e., $<50 \%$ ) there was a marked reduction in flow cytometric forward scatter, indicating a reduction in cell size, and an increase in side scatter, indicating an increase in cell granularity after stromal cultures $(A$, lower plots $)$.

Changes in cell morphology were accompanied by a decrease in cellular DNA content ( $B$, lower plots). By contrast, in cases with better cell recovery (i.e., $>91 \%$ ) after stromal cultures, no significant changes in light scattering ( $A$, upper plots) or DNA content ( $B$, upper plots) were detected. In addition, DNA fragmentation in multiples of 180 basepairs was visible by gel electrophoresis after $72 \mathrm{~h}$ of culture in cases with poor cell recovery $(C$, lane 1$)$, but not in cases with better cell growth (C, lane 2; $M W$, molecular weight marker of multiples of 123 base-

pairs). Finally, severe deterioration of cell morphology was documented by scanning electron microscopy after $5 \mathrm{~d}$ of culture $(D, 1)$, which markedly contrasted with the morphologic features of cells in cases with better cell recovery $(D, 2)$. 
Table II. Association of the Proliferative Fraction of Leukemic Cells with Cell Recovery after Culture on Stromal Layers

\begin{tabular}{lccc}
\hline & \multicolumn{2}{c}{ Percent viable cells in S phase } & \\
\cline { 2 - 3 } Sample & Before culture & After 3-5 d of culture & $\begin{array}{c}\text { Percent cells recovered } \\
\text { after 7 d of culture* }\end{array}$ \\
\hline 1 & 16.3 & 16.8 & 6 \\
2 & 4.5 & 21.0 & 7 \\
3 & 10.5 & 21.1 & 24 \\
4 & 7.3 & 16.3 & 34 \\
5 & 2.4 & 13.3 & 105 \\
6 & 2.3 & 7.0 & 106 \\
7 & 4.0 & 10.0 & 111 \\
8 & 9.3 & 12.3 & 143 \\
9 & 9.5 & 14.7 & 178
\end{tabular}

* Relative to the number of cells originally seeded.

In parallel experiments in which cells were cultured in the absence of stroma, apoptosis developed rapidly in most cases. Median cell recovery after $7 \mathrm{~d}$ of culture in 69 cases was $<1 \%$ (range, $<1-122 \%$ ).

Relation of leukemic cell survival on stroma to presenting clinicobiologic features. Table I shows the percentage of cell recovery by the clinical and biologic features commonly measured at diagnosis of ALL. Significant differences were found in comparisons between prognostic categories of leukemic cell ploidy, leukocyte count, and serum lactate dehydrogenase (LDH) level. The correlation with ploidy was striking. Of the 18 hyperdiploid cases (modal chromosome numbers of 51-65), only one showed higher growth potential (i.e., a cell recovery rate $>91 \%$ ), as compared with 34 of 51 in other ploidy groups $(P<0.001)$. As might be expected, a larger burden of leukemic cells was closely related to lymphoblast survival on stromal layers: 14 of 17 cases with leukocyte counts $>50 \times 10^{9} /$ liter had cell recovery rates $>91 \%$, in contrast to only 21 of 53 with lower counts $(P=0.004)$. A similar relationship was demonstrated for higher serum LDH levels, another indicator of the size of the leukemic cell infiltrate.

Higher rates of cell recovery were common in small subgroups of cases with exceptionally poor prognoses (17). For instance, seven of the eight cases with either the Philadelphia chromosome or an abnormality of the 11q23 chromosomal region were characterized by cell recoveries of $>91 \%$. The single case of Philadelphia chromosome-positive ALL with a

Table III. Univariate Analysis of Selected Prognostic Features in the 70 Patients Studied

\begin{tabular}{lll}
\hline \multicolumn{1}{c}{ Adverse feature } & \multicolumn{1}{c}{ Odds ratio $(95 \% \mathrm{CI})$} & $P$ value \\
\hline High cell recovery $(>91 \%)$ & $6.03(2.44,14.92)$ & 0.0002 \\
Leukocyte count $>50 \times 10^{9} /$ liter & $5.19(1.70,15.84)$ & 0.0140 \\
Presence of CNS leukemia & $6.35(1.75,23.08)$ & 0.0150 \\
Male sex & $3.10(1.24,7.80)$ & 0.0173 \\
Age $<1$ or $>10$ yr & $5.01(1.56,16.12)$ & 0.0182 \\
Nonhyperdiploidy $(<51$ chromosomes $)$ & $2.32(0.84,6.39)$ & 0.1130 \\
Pre-B immunophenotype & $1.67(0.63,4.43)$ & 0.3288 \\
Serum LDH $>770$ U/liter & $1.34(0.45,4.01)$ & 0.6123 \\
\end{tabular}

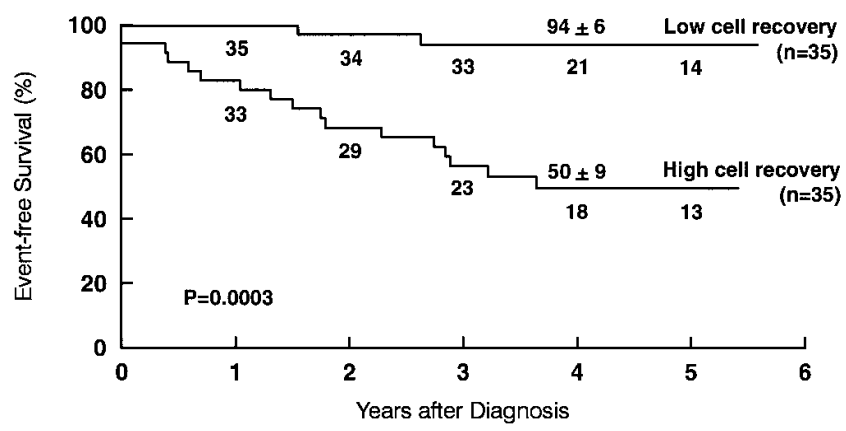

Figure 3. Kaplan-Meier comparison of event-free survival among children grouped by percentage of lymphoblasts recovered from 7-d stromal layer cultures. High cell recovery: $>91 \%$; low cell recovery: $\leq 91 \%$. 4-yr estimates ( \pm SE) are shown on the curves; numbers along the curves denote patients at risk of failure at the beginning of each yearly interval.

relatively low recovery rate $(18 \%)$ had a hyperdiploid chromosome number. Leukemic lymphoblasts with $<46$ chromosomes and those from infants $<1 \mathrm{yr}$ of age consistently survived well on stromal layers (Table I).

The percentage of S-phase cells at the time of diagnosis was not significantly related to cell recovery $(P=0.145$; Table I). However, this result did not exclude the possibility that higher cell recoveries after culture on stromal layers might reflect the selection of subclones with high proliferative activity. To the contrary, among viable lymphoblasts recovered from 3-5-d cultures on stromal layers $(n=9)$, percentages of S-phase cells determined were higher in cases with low recovery rates (Table II). Thus, cell recoveries after culture on stroma did not reflect the rate of DNA synthesis during culture.

Cell recovery after culture on stromal layers as a predictor of clinical outcome. All 70 patients were included in the analysis of event-free survival (Fig. 3). Within $4 \mathrm{yr}$ from the start of treatment, 17 patients in the group with $>91 \%$ leukemic cell recovery had an adverse survival event, compared with only two in the worse cell recovery cohort. The estimated proportions of patients surviving event-free at $4 \mathrm{yr}$ of follow-up were $50 \pm 9 \%(\mathrm{SE})$ and $94 \pm 6 \%$, respectively $(P=0.0003$ for the overall Kaplan-Meier comparisons). Among the patients with adverse survival events, there was no linear relation between percentage of cell recovery and time of treatment failure (data not shown). Event-free survival estimates did not differ significantly between the 70 eligible patients and the remaining 77 B-lineage ALL patients who also were treated in the same protocol $(P=0.41$; curves not shown). The percentage of cell recovery from 7 -d cultures without stroma did not predict clinical outcome (69 samples studied; $P=0.96$; data not shown).

In the univariate statistical analysis, cell recovery after culture on stroma and four other patient characteristics (leukocyte count, CNS involvement at diagnosis, age, and sex) were significantly related to clinical outcome (Table III). The odds of failure (no remission, relapse, or death due to any cause) for patients in the unfavorable category of cell survival on stroma were 6.03 times those in the opposite category (95\% CI, 2.4414.92). Only two of the significant competing factors, CNS involvement at diagnosis and sex, showed an effect on outcome after adjustment for survival on stroma, whereas the reverse adjustments failed to abolish or substantially weaken the predictive strength of the stromal assay (Table IV). Combined ad- 


\begin{tabular}{|c|c|c|c|c|}
\hline Adverse feature & Odds ratio $(95 \% \mathrm{CI})^{\ddagger}$ & $P$ value & Odds ratio $(95 \% \mathrm{CI})^{\S}$ & $P$ value \\
\hline High cell recovery $(>91 \%)$ & - & - & $6.03(2.44,14.92)^{\|}$ & 0.0002 \\
\hline $\mathrm{WBC}>50 \times 10^{9} /$ liter & $2.06(0.77,5.51)$ & 0.2167 & $5.09(1.87,13.82)$ & 0.0016 \\
\hline Age $<1$ or $>10 \mathrm{yr}$ & $3.57(1.18,10.84)$ & 0.0571 & $5.24(2.09,13.10)$ & 0.0002 \\
\hline Presence of CNS leukemia & $4.27(1.27,14.38)$ & 0.0326 & $4.71(1.85,12.00)$ & 0.0008 \\
\hline Male sex & $3.53(1.39,8.99)$ & 0.0077 & $6.80(2.72,16.98)$ & 0.0001 \\
\hline
\end{tabular}

* Limited to variables attaining statistical significance in Table III. Simultaneous adjustment for competing covariates yielded an odds ratio of 4.40 (95\% CI, 1.25-15.49; $P=0.021) ;{ }^{*}$ each factor adjusted for high cell recovery $(>91 \%) ;{ }^{\S}$ high cell recovery adjusted for each factor; ${ }^{\|}$unadjusted ratio.

justment for all significant prognostic factors confirmed the independent prognostic significance of leukemic cell survival in culture (odds ratio $=4.4 ; 95 \%$ confidence interval, $1.25-15.49$; $P=0.021)$.

\section{Discussion}

Acute lymphoblastic leukemia is thought to arise from a process in which multiple transformation events alter the ability of lymphoid progenitors to survive, proliferate and differentiate (18-20). We took advantage of recently developed tissue culture techniques permitting reconstruction of the bone marrow microenvironment in vitro to assess the growth potential of leukemic B-lymphoblasts. The recovery of viable cells after $7 \mathrm{~d}$ of culture showed wide variability, ranging from $<1$ to $292 \%$ (median, 91\%). These differences appear to reflect the intrinsic survival requirements, rather than the proliferative activity of leukemic cell populations. We favor this interpretation because of the lack of correlation between the percentage of S-phase cells and the rate of cell recovery (Tables I and II), together with the higher apoptotic death rate in cases with poorer survival on bone marrow stroma.

A major advantage of this assay is that leukemic cells are counted precisely by flow cytometry at the beginning and end of the cultures. Immunophenotypic analysis allows rare normal $\mathrm{T}$ lymphocytes to be excluded from the final results. Anomalous cell growth dependent on unknown factors in animal sera was avoided by performing all cultures in serum-free medium, thus ensuring the reproducibility of the assay. One variable that may have influenced cell recoveries was the use of different bone marrow donors as a source of stroma. However, all cultures were performed with morphologically identical and confluent stromal layers, and comparable levels of cell viability were attained with stroma from different donors.

Our findings indicate that leukemic cell survival on bone marrow stroma provides a more reliable indicator of prognosis than other, more commonly measured variables in ALL (4). At $4 \mathrm{yr}$ of follow-up, only $50 \%$ of the patients with higher cell recoveries had no adverse events, compared with more than $90 \%$ in the group with lower recoveries. In our multivariate analysis, cell growth on stroma emerged as the single best predictor of clinical outcome in patients treated on a contemporary protocol of leukemia therapy. This result has several theoretical explanations. Most obvious is the greater likelihood of multidrug resistance in more rapidly expanding leukemic cell populations (21). It is also possible that cells with less stringent survival requirements could infiltrate and expand within extramedullary sites not readily accessible to antileukemic drugs. Finally, more stringent survival requirements could underlie a propensity for apoptosis, resulting in superior responses to cytotoxic chemotherapy. This point is well-illustrated by experience with hyperdiploid ALL, described below.

For more than a decade, hyperdiploidy (51-65 chromosomes) has been recognized as a highly favorable prognostic feature in childhood ALL (17, 22, 23), although the basis for this status has not been clear. Some investigators have postulated that hyperdiploid blast cells have reduced "tumorigenicity" (24) or a greater "tendency towards terminal differentiation" (25), but these concepts lack strong experimental support. Our results suggest that an increased tendency to undergo apoptosis may account for the high cure rates commonly achieved in this biologic subtype of ALL. It should be noted that 2 of our 18 hyperdiploid cases had an adverse survival event, consistent with results in larger trials (1). Cell recovery rates in both of these cases were higher than in the remaining 16 cases ( 74 and $133 \%$ vs. $<1-56 \%$ ), emphasizing the potential value of our bioassay for identifying rare high-risk patients in otherwise low-risk groups. Conversely, a low cell recovery might distinguish patients in poor-prognosis groups who do not require intensified treatment (17).

To summarize, we have described a prognostically important bioassay based on the culture of B-lineage leukemic cells on bone marrow-derived stromal layers, a microenvironment that approximates in vivo conditions. Histopathologic detection of leukemic cells in immunodeficient mice $12 \mathrm{wk}$ after inoculation has also been suggested as a means of identifying ALL patients with a higher risk of relapse (26). However, the stromal layer assay offers clear advantages for use in planning risk-directed therapy, as its results are available in $1 \mathrm{wk}$. It is also ideally suited for determining the drug sensitivity of leukemic cells $(7,8,27,28)$ allowing one to correlate this feature with cell growth potential in the same system.

\section{Acknowledgments}

We thank Ms. E. Coustan-Smith for DNA content analysis, Dr. K.G. Murti for scanning electron microscopy, Dr. J. Boyett for advice on statistical analysis, and Mr. J. Gilbert for his critical review of the manuscript.

This work was supported by grants RO1-CA58297, P30-CA21765 (CORE), and CA20180 from the National Cancer Institute, and by the American Lebanese Syrian Associated Charities.

\section{References}

1. Pui, C.H., and W.M. Crist. 1994. Biology and treatment of acute lymphoblastic leukemia. J. Pediatr. 124:491-503.

2. Schorin, M.A., S. Blattner, R.D. Gelber, N.J. Tarbell, M. Donnelly, V. Dalton, H.J. Cohen, and S.E. Sallan. 1994. Treatment of childhood acute lym- 
phoblastic leukemia: results of Dana-Farber Cancer Institute/Children's Hospital Acute Lymphoblastic Leukemia Consortium protocol 85-01. J. Clin. Oncol. 12:740-747.

3. Rivera, G.K., S.C. Raimondi, M.L. Hancock, F.G. Behm, C.H. Pui, M. Abromowitch, J. Mirro, Jr., J.S. Ochs, A.T. Look, D.L. Williams, et al. 1991. Improved outcome in childhood acute lymphoblastic leukaemia with reinforced early treatment and rotational combination chemotherapy. Lancet. i:61-66.

4. Pui, C.H. 1995. Childhood leukemias. N. Engl. J. Med. 332:1618-1630.

5. Manabe, A., E. Coustan-Smith, F.G. Behm, S.C. Raimondi, and D. Campana. 1992. Bone marrow-derived stromal cells prevent apoptotic cell death in B-lineage acute lymphoblastic leukemia. Blood. 79:2370-2377.

6. Manabe, A., K.G. Murti, E. Coustan-Smith, M. Kumagai, F.G. Behm, S.C. Raimondi, and D. Campana. 1994. Adhesion-dependent survival of normal and leukemic human B lymphoblasts on bone marrow stromal cells. Blood. 83: 758-766.

7. Campana, D., A. Manabe, and W.E. Evans. 1993. Stroma-supported immunocytometric assay (SIA): a novel method for testing the sensitivity of acute lymphoblastic leukemia cells to cytotoxic drugs. Leukemia. 7:482-488.

8. Manabe, A., E. Coustan-Smith, M. Kumagai, F.G. Behm, S.C. Raimondi, C-H. Pui, and D. Campana. 1994. Interleukin-4 induces programmed cell death (apoptosis) in cases of high risk acute lymphoblastic leukemia. Blood. 83:17311737.

9. Kumagai, M., E. Coustan-Smith, D.J. Murry, O. Silvennoinen, K.G. Murti, W.E. Evans, F. Malavasi, and D. Campana. 1995. Ligation of CD38 suppresses human B lymphopoiesis. J. Exp. Med. 181:1101-1110.

10. Young, L., C. Alfieri, K. Hennessey, H. Evans, C. O'Hara, K.C. Anderson, J. Ritz, R.S. Shapiro, A. Rickinson, E. Kieff, and J.I. Cohen. 1989. Expression of Epstein-Barr virus transformation-associated genes in tissues of patients with EBV lymphoproliferative disease. N. Engl. J. Med. 321:1080-1085.

11. Evans, W.E., J. Rodman, M.V. Relling, W.R. Crom, G.K. Rivera, W.M. Crist, and C-H. Pui. 1991. Individualized dosages of chemotherapy as a strategy to improve response for acute lymphocytic leukemia. Semin. Hematol. 28(Suppl. 4):15-21.

12. Peto, R., M.C. Pike, P. Armitage, N.E. Breslow, D.R. Cox, S.V. Howard, N. Mantel, K. McPherson, J. Peto, and P.G. Smith. 1977. Design and analysis of randomized clinical trials requiring prolonged observations of each patient. II. Analysis and examples. Br. J. Cancer. 35:1-39.

13. Early Breast Cancer Trialists' Collaborative Group. Treatment of Early Breast Cancer. 1992. Vol. 1. Worldwide Evidence 1985-1990. Section 5. Oxford University Press, New York/London.

14. Lahti, J.M., J. Xiang, L.S. Heath, D. Campana, and V.J. Kidd. 1995. PITSLRE protein kinase activity is associated with apoptosis. Mol. Cell. Biol. 15:1-11.
15. Darzynkiewicz, Z., S. Bruno, G. Del Bino, W. Gorczyka, M.A. Hotz, P. Lassota, and F. Traganos. 1992. Features of apoptotic cells measured by flow cytometry. Cytometry. 13:795-805.

16. Wyllie, A.H., J.F.R. Kerr, and A.R. Currie. 1980. Cell death: the significance of apoptosis. Int. Rev. Cytol. 68:251-306.

17. Pui, C.H., W.M. Crist, and A.T. Look. 1990. Biology and clinical significance of cytogenetic abnormalities in childhood acute lymphoblastic leukemia. Blood. 76:1449-1463.

18. Greaves, M.F. 1986. Differentiation-linked leukemogenesis in lymphocytes. Science (Wash. DC). 234:697-701.

19. Korsmeyer, S.J. 1992. Bcl-2 initiates a new category of oncogenes: regulators of cell death. Blood. 80:879-886.

20. Cline, M.J. 1994. The molecular basis of leukemia. N. Engl. J. Med. 330: 328-336.

21. Goldie, J., and A. Coldman. 1985. Genetic instability in the development of drug resistance. Semin. Oncol. 12:222-230.

22. Secker-Walker, L.M., S.D. Lawler, and R.M. Hardisty. 1978. Prognostic implications of chromosomal findings in acute lymphoblastic leukemia at diagnosis. Br. Med.J. 2:1529-1530.

23. Trueworthy, J., J. Shuster, T. Look, W. Crist, M. Borowitz, A. Carroll, L. Frankel, M. Harris, H. Wagner, M. Haggard, et al. 1992. Ploidy of lymphoblasts is the strongest predictor of treatment outcome in B-progenitor cell acute lymphoblastic leukemia of childhood: a Pediatric Oncology Group study. $J$. Clin. Oncol. 10:606-613.

24. Tsuchiya, H., I. Matsuda, and Y. Kaneko. 1991. Why does childhood acute lymphoblastic leukemia with hyperdiploidy show a favorable prognosis? Cancer Genet. Cytogenet. 50:273-275.

25. Smets, L.A., R.M. Slater, H. Behrendt, M.B. Van't Veer, and J. HomanBlok. 1985. Phenotypic and karyotypic properties of hyperdiploid acute lymphoblastic leukemia of childhood. Br. J. Hematol. 61:113-120.

26. Uckun, F.M., H. Sather, G. Reaman, J. Shuster, V. Land, M. Trigg, R. Gunther, L. Chelstrom, A. Bleyer, P. Gaynon, and W. Crist. 1995. Leukemic cell growth in SCID mice as a predictor of relapse in high-risk B-lineage acute lymphoblastic leukemia. Blood. 85:873-878.

27. Manabe, A., T. Yi, M. Kumagai, and D. Campana. 1993. Use of stromasupported cultures of leukemic cells to assess antileukemic drugs. I. Cytotoxicity of interferon alpha in acute lymphoblastic leukemia. Leukemia. 7:19001905

28. Kumagai, M., A. Manabe, E. Coustan-Smith, R.L. Blakley, W.T. Beck, V.M. Santana, F.G. Behm, S.C. Raimondi, and D. Campana. 1994. Use of stroma-supported cultures of leukemic cells to assess antileukemic drugs. II Potent cytotoxicity of 2-chloro-deoxyadenosine in acute lymphoblastic leukemia. Leukemia. 8:1116-1123. 